Review

\title{
Carbon-Based Nanomaterials Functionalized with Ionic Liquids for Microextraction in Sample Preparation
}

\author{
Theodoros Chatzimitakos and Constantine Stalikas * \\ Laboratory of Analytical Chemistry, Department of Chemistry, University of Ioannina, Ioannina 45110, Greece; \\ chatzimitakos@outlook.com \\ * Correspondence: cstalika@cc.uoi.gr; Tel.: +30-26510-08414; Fax: +30-26510-08796
}

Academic Editors: Jared L. Anderson and Victoria F. Samanidou

Received: 9 February 2017; Accepted: 4 April 2017; Published: 10 April 2017

\begin{abstract}
A large number of carbon-based nanomaterials has been investigated as sorbents in sample preparation, including fullerenes, carbon nanotubes, nanofibers, nanohorns and graphene, as well as their functionalized forms. Taking into account their properties, carbon-based nanomaterials have found a wide range of applications in different sample preparation techniques. Ionic liquids, as an alternative to environmentally-harmful ordinary organic solvents, have attracted extensive attention and gained popularity in analytical chemistry covering different fields like chromatography, electrochemistry and (micro)extraction. Some of the properties of ionic liquids, including polarity, hydrophobicity and viscosity, can be tuned by the proper selection of the building cations and anions. Their tunable nature allows the synthesis of tailor-made solvents for different applications. This review provides a snapshot of the most important features and applications of different carbon-based nanomaterials functionalized with ionic liquids for sample preparation. Emphasis is placed on the description of the different works that have provided interesting results for the use of graphene and carbon nanotubes, in this analytical field.
\end{abstract}

Keywords: graphene; carbon nanotubes; ionic liquid; magnetic; microextraction; sample preparation

\section{Introduction}

The selection and optimization of the appropriate sample preparation procedure qualifies as essential for the development of a successful method. The modern trend for 'greener' chemical analyses has led to the development of microscale extraction approaches towards minimizing the organic solvent consumption, while maximizing sample throughput and extraction efficiency of the analytes. Microextraction is an extraction technique where the volume of the extracting phase is very small in relation to the volume of the sample [1]. It is not necessarily an exhaustive extraction procedure, in contrast to the classical liquid-liquid extraction and solid-phase extraction (SPE), signifying that possibly only a fraction of the analyte may finally be subjected to analysis. Hence, it is not surprising that microextraction, in the modes of solid-phase microextraction (SPME), dispersive solid-phase microextraction (DSPE), magnetic solid-phase extraction (MSPE), pipette-tip solid-phase extraction (PT-SPE), etc., has come to the forefront of analytical chemistry in the past few years.

Carbon-based nanomaterials have been extensively used in analytical applications [2]. A large number of them have been investigated as sorbents in sample preparation, including fullerenes, carbon nanotubes, nanofibers, nanohorns and graphene, as well as their chemically-modified analogues. The characteristic structures of carbon-based nanomaterials allow them to interact with molecules via non-covalent forces, such as hydrogen bonding, $\pi-\pi$ stacking, electrostatic forces, van der Waals forces and hydrophobic interactions. Taking into account the aforementioned possibilities, carbon-based 
nanomaterials have found a wide range of applications in different sample preparation techniques. Although the reasons for the selection of a particular allotrope over another are still being discussed, a wide variety of carbon-based materials is available and applicable to analytical procedures.

Since the first report in 1991 [3], carbon nanotubes (CNTs) have shown great possibilities for a wide variety of processes and applications. The combination of structures, dimensions and topologies has provided physical and chemical properties that are unparalleled by most known materials. Their applications have also reached the analytical chemistry field, in which CNTs are being used as matrices in matrix-assisted laser desorption ionization, as stationary phases in separation techniques (gas chromatography, high performance liquid chromatography and capillary electrochromatography and capillary electrophoresis), as well as new SPE materials [4,5]. As regards this last application, the number of works has considerably increased in the last ten years.

Graphene, discovered in 2004, is another kind of novel and particularly fascinating carbon material, which has sparked a tremendous amount of research from both the experimental and theoretical scientific communities in recent years [6]. Because of its extraordinary electrical properties and very high specific surface area, graphene $(\mathrm{G})$ and graphene oxide $(\mathrm{GO})$ have been widely applied as electrode materials, adsorbents in solid-phase (micro)extraction and magnetic solid-phase extraction.

Ionic liquids (ILs) have attracted extensive attention and gained popularity in analytical chemistry, as an alternative to environmentally-harmful ordinary organic solvents, covering different application fields like chromatography, electrochemistry and (micro)extraction [7]. The potential of ILs in chemistry is related to their unique properties as non-molecular solvents, negligible vapor pressure associated with high thermal stability, tunable viscosity, miscibility with water and organic solvents and good extractability for various organic compounds and metal ions. Their polarity, hydrophobicity, viscosity and other chemical and physical properties can be tailored through the choice of the cationic and anionic constituents [8]. Functional materials, which consist of ILs and magnetic composites, presented excellent properties for extraction [9]. However, at elevated temperatures, the viscosity of the IL is reduced, resulting in a flowing state in which the IL can be lost. To overcome it, polymeric ILs (PILs) were synthesized and studied extensively. The PILs have higher thermal stability compared to monomeric ILs and, therefore, more resistance to flow. Additionally, PILs are tunable through functionalization of the IL monomers, therefore altering their physicochemical properties along with their extractive capabilities [10].

Combining the two above-mentioned major fields, i.e., carbon-based nanomaterials and ILs, it is possible to design and develop new extracting phases with outstanding properties for microextraction purposes. The carbon-based nanomaterials modified with ILs are expected to possess the advantages of both components of the functionalized material, resulting in new, advanced adsorbents with tunable microextraction capabilities. This review provides an updated and critical snapshot of the applications of the carbon-based nanomaterials in microextraction, as an integral step of sample preparation. Attention is paid to the discussion of cases dealing with IL-functionalized graphene and multi-walled carbon nanotubes, which are examined according to the microextraction mode they support (Figure 1) and illustrate novel concepts and promising applications. 


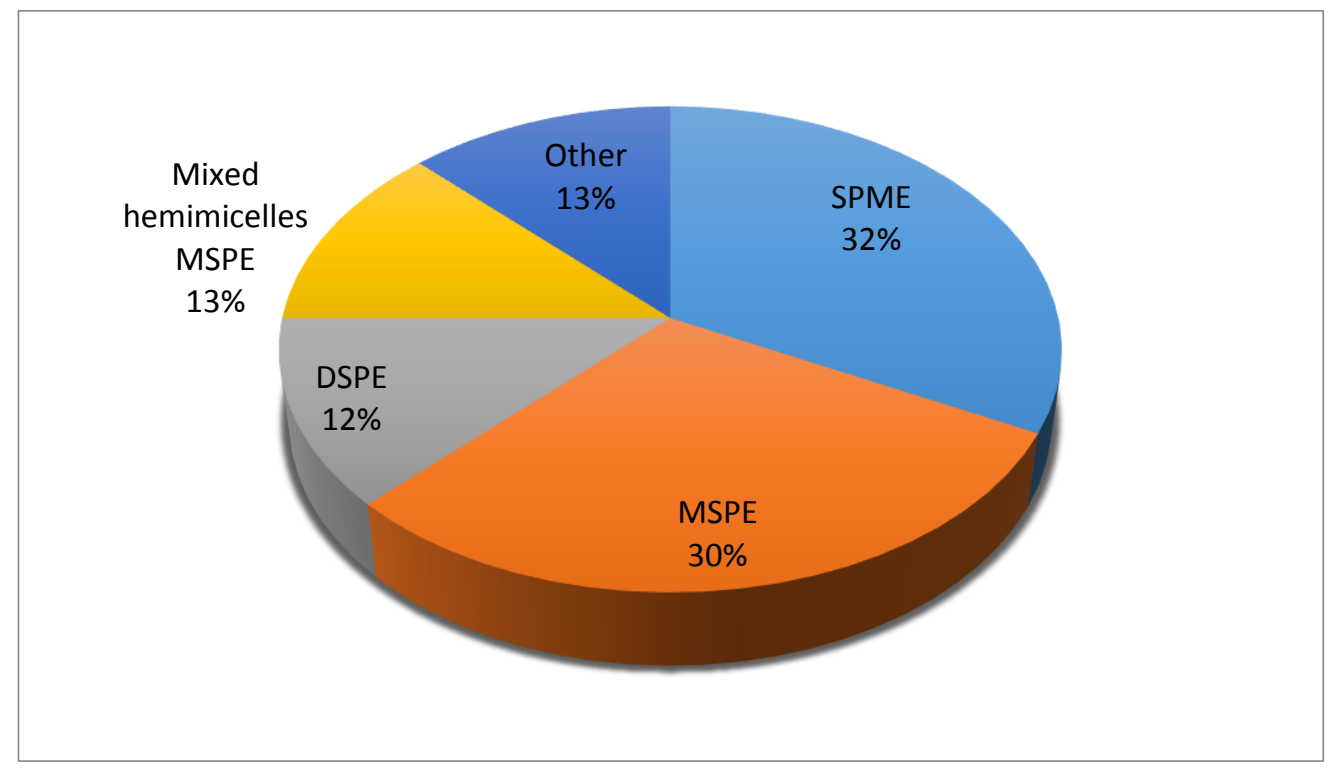

Figure 1. Main microextraction techniques based on carbon nanomaterials functionalized with ionic liquids. Pie chart showing the percentage of published articles referring to them during the period of 2013-2016.

\section{Ionic Liquid-Coated Graphene-Based Nanomaterials}

\subsection{Solid-Phase Microextraction}

In SPME, the fiber coating, which is the heart of the technique to extract the compounds from samples, consists of a liquid (polymer), a solid (sorbent) or a combination of both. The type of coating plays a crucial role in the extraction and desorption process, since its efficiency depends on the distribution constant of the analytes between the sample and the stationary phase. In addition, it provides some selectivity to the SPME process towards the analytes versus other matrix compounds. Fibers containing the IL-G/CNTs composites are reported to be stable, under headspace and direct injection mode. So far, various procedures have been proposed to prepare stainless steel fibers for SPME coated with GO, functionalized either with monomeric or polymeric ILs. Hou et al. coated a stainless steel fiber with GO and then tried four different coatings based on ILs: two monomeric coatings with 1-aminoethyl-3-methylimidazolium bromide or bis(trifluoromethanesulfonyl)imide ([NTf $\left.\mathrm{NT}_{2}\right]$ and two coatings based on poly(1-vinyl-3-hexylimidazolium) bromide or [ $\left.\mathrm{NTf}_{2}\right]$ [10]. Then, they evaluated their capabilities for the headspace SPME ((HS)SPME) of polycyclic aromatic hydrocarbons (PAHs) and phthalate esters. It was proven that an in situ anion exchange process to alter the anion of the IL from bromide to $\left[\mathrm{NTf}_{2}\right]$ has merits in terms of the simplicity of synthesis and extraction capability towards the target analytes. Obviously, altering the anion of the ILs (bromide) to a more hydrophobic analogue ([NTf $\left.f_{2}\right]$ ) directly affects the extraction capability of the fiber towards the selected analytes, enhances the overall extraction efficiency and lowers the detection limits. The superiority of the PIL-coated GO-stainless steel fibers over the monomeric analogues was underlined, as regards the SPME extraction of PAHs and phthalates.

To improve the extraction efficiency of the SPME procedure for PAHs, 1-methyl-3-[3-(trimethoxysilyl) propyl] imidazolium chloride was employed as a cross-linking agent, between a silanol functionalized silver-coated stainless steel fiber and GO. In this way, layers of GO grew on the fiber [11]. The IL greatly enhanced the bonding strength between the fiber and the GO layers, resulting in a stable coating. The coating on the fiber was achieved via a layer-by-layer method, by repeating a cycle of immersing the silanol functionalized fiber in an IL solution, drying and then immersing it in a GO solution, five times. The layer-by-layer method provides convenience to control the number of GO layers and, 
hence, the extraction efficiency of the SPME procedure. The developed SPME fiber was used to extract effectively certain PAHs from rain and river water, in a direct-immersion SPME ((DI)SPME) procedure.

Another interesting case is the immobilization of a metal-organic framework-IL functionalized graphene on an etched fiber [12]. The metal-organic frameworks have a high surface area, porosity and enable the in-pore and outer-surface functionalization, which in turn, allows their use as sorbents in sample preparation. The low mechanical and chemical stability of the metal-organic frameworks is improved by introducing mechanically-durable materials, such as graphene. In the present case, the morphology of the resulting fiber showed that the presence of the IL-G did not interfere with the growth of the metal-organic framework, in terms of structure and crystal shape. On the contrary, the presence of the IL-G enhanced the uniformity of the microcrystals' structure, along with their mechanical stability. The combination of a metal-organic framework and an IL-G resulted in a fiber that combined the advantageous properties of all three components. To take advantage of the aforementioned benefits, an analytical method for the (HS)SPME extraction and detection of antibiotics in food and biological matrixes was developed. Because of the presence of IL, the results were improved a great deal, as the enrichment factors (EFs) revealed after conducting relevant experiments. In addition, the presence of $G$ enhanced the EFs by 4-7-fold compared to a fiber coated only with the metal-organic framework.

An alternative approach of functionalized SPME fiber was employed by Sun et al. [13], who prepared a PIL monolith doped with GO attached to a fiber, prior to the (DI)SPME, instead of directly coating the stainless steel fiber. This novel type of coating was used to extract phenols from environmental aqueous samples with success. Finally, Wu et al. developed a poly(3,4-ethylenedioxythiophene) (PEDOT) coating doped with a GO-IL composite (1-hydroxyethyl-3- methyl imidazolium [ $\left[\mathrm{NTf}_{2}\right]$ was the IL used), for SPME purposes [14]. The GO-IL-PEDOT coating was electrodeposited on the surface of the fiber using cyclic voltammetry, and the resulting coating, which had many pores and a wrinkled structure, was improved compared to similar materials, in terms of surface area. The high porosity of the coating, alongside with the rich $\pi$-electron stacking of the coating, favored the applicability of the new fiber to SPME procedures. To prove this, the authors developed an analytical method aiming to determine benzene derivatives in industrial wastewater and environmental water samples, after their (HS)SPME. The fiber was superior to commercially available fibers (2-4-times better for the extraction of benzene derivatives compared to a polydimethylsiloxane fiber) and had a long lifetime, greatly reducing in this way the cost of the proposed method.

Summarizing, only a few analytical methods have been developed that utilize IL-G composite nanomaterials in SPME, either in headspace or direct-immersion mode (a complete list can be seen in Table 1). The developed methods have been applied to the determination of PAHs, phthalate esters, phenols, benzene derivatives and antibiotics in water (mainly), food and biological samples. The facile approaches have the merits of low limits of detection (LODs) (lower than others from previously reported methods), short extraction time and a wide linear range. Additionally, the analytical performances of the new methods are better than those of commercially available fibers, in terms of LODs and EFs [11,14], while the functionalized fibers can be reused with an insignificant decrease in the extraction efficiency [12]. From the studies conducted, it was apparent that the presence of the IL-G composites on the surfaces of the fibers is advantageous and facilitates the improvement of the SPME efficiency, since the resulting fibers combine the advantages of both ILs and G. The comparison of the analytical performances of the experiments, conducted in the absence of the IL or the G, proved that the results are less satisfactory than those in the presence of IL-G, underlining the role of IL. 
Table 1. Microextraction techniques employing IL-G/IL-GO composite nanomaterials.

\begin{tabular}{|c|c|c|c|c|c|c|c|}
\hline Ionic Liquid & $\begin{array}{l}\text { Microextraction } \\
\text { Technique }\end{array}$ & Matrix & Target Analytes & LOD $(\mu \mathrm{g} / \mathrm{L})$ & Recoveries (\%) & $\begin{array}{l}\text { Instrumental } \\
\text { Analytical System }\end{array}$ & Reference \\
\hline poly(1-vinyl-3-hexylimidazolium-[NTf 2$]$ ) & (HS)SPME & food-wrap, potato & PAHs and phthalate esters & $0.015-0.025$ & $78.3-101.7$ & GC-FID & [10] \\
\hline $\begin{array}{l}\text { 1-methyl-3-[3-(trimethoxysilyl)propyl] } \\
\text { imidazolium chloride }\end{array}$ & (DI)SPME & rain and river water & PAHs & $0.05-0.10$ & $92.3-120$ & GC-FID & [11] \\
\hline $\begin{array}{l}\text { 1-(3-aminopropyl)-3-methylimidazolium } \\
\text { bromide }\end{array}$ & (HS)SPME & milk, honey, urine and serum & antibiotics & $0.014-0.019$ & $82.3-103.2$ & GC-FID & [12] \\
\hline $\begin{array}{l}\text { 1-(3-aminopropyl)-3-(4-vinylbenzyl) } \\
\text { imidazolium 4-styrenesulfonate }\end{array}$ & (DI)SPME & $\begin{array}{l}\text { groundwater of industrial park } \\
\text { and river water }\end{array}$ & phenols & $0.2-0.5$ & $75.5-113$ & HPLC-DAD & [13] \\
\hline $\begin{array}{l}\text { 1-hydroxyethyl-3-methyl } \\
\left.\text { imidazolium-[NTf }{ }_{2}\right]\end{array}$ & (HS)SPME & $\begin{array}{l}\text { petrochemical, printing, dyeing } \\
\text { wastewater and lake water }\end{array}$ & benzene derivatives & $0.010-0.019$ & $82.3-108.3$ & GC-FID & [14] \\
\hline $\begin{array}{l}\text { 1-butyl-3-aminopropyl } \\
\text { imidazolium chloride }\end{array}$ & DSPE & $\begin{array}{l}\text { effluent municipal wastewater } \\
\text { treatment plant water, river and } \\
\text { lake water }\end{array}$ & steroids, $\beta$-blockers & $0.007-0.023$ & $87-98$ & HPLC-DAD & [15] \\
\hline
\end{tabular}




\subsection{Other Microextraction Technique}

Aside from immobilizing the IL-G on the surface of a fiber, GO-IL composite nanomaterials can also be used directly as sorbent materials. In this context, a microextraction method has been published, utilizing an IL-GO composite material in DSPE, which objectively follows the principles of the microextraction procedure. Specifically, Serrano et al. functionalized graphene with 1-butyl-3-aminopropyl imidazolium chloride in a one-pot synthesis, where the IL, graphene oxide and $N, N^{\prime}$-dicyclohexylcarbodiimide were stirred for $24 \mathrm{~h}$ [15]. The characterization of the synthesized material verified that the structure of the final product was similar to that of graphene, hinting at a high specific surface area of the final product and making it suitable for microextraction purposes. The monomeric IL-GO composite was used as an adsorbent, for the first time, in the DSPE procedure, and the authors developed a method for the simultaneous detection of steroids and $\beta$-blockers. Under the same procedure, $\mathrm{G}$ was unable to extract any of the target analytes, while $\mathrm{GO}$ could extract only three out of the ten analytes. Therefore, the presence of the IL was responsible for the successful extraction of the target analytes, and exceedingly high EFs were achieved for all analytes. The LODs achieved rival those of the classical SPE and SPME methods.

\section{Ionic Liquid-Coated Carbon Nanotubes-Based Materials}

\subsection{Solid-Phase Microextraction}

In addition to graphene, which has already been commented on, adsorbents for microextraction purposes have been developed based on multi-walled CNTs (Table 2). The functionalization of CNTs with PILs follows two main, simple procedures, which are worth discussion: the covalent and the non-covalent functionalization [16]. A representative example of the covalent PIL functionalization of CNTs is the work presented by Cordero-Vaca et al. who functionalized nitinol wires (Ni/Ti alloy) with a crosslinked PIL-CNT coating [17]. The crosslinked PIL consisted of the monocationic IL 1-vinyl-3-butylimidazolium [ $\left[\mathrm{NTf}_{2}\right]$ as the monomer and the dicationic 1,12-di(3-vinylimidazolium) dodecane $\left[\mathrm{NTf}_{2}\right]$ as the IL crosslinker. Automation for the (DI)SPME of phenols and PAHs was possible once the wires were attached to a holder.

Bucky gels are gelatinous composite materials consisting of CNTs and ILs. In a different way than before, Zhang et al. coated a fused silica SPME fiber with a cross-linked PIL bucky gel containing CNTs [18]. To do so, the monomer 1-vinyl-3-butylimidazolium [NTf ${ }_{2}$ ] and the cross-linker 1,12-di(3-vinylimidazolium) dodecane [NTf 2 , along with CNTs (between $3 \%$ and $8 \%(w / w)$ ) were ground to achieve complete mixing of the components, followed by the addition of an initiator and dip-coating of the fiber. The manufactured coated fibers were tested for the (HS)SPME of eight PAHs. A PIL-based coating without the addition of CNTs was found to be inferior compared to the commercially available polydimethylsiloxane fiber for the extraction of PAHs. The addition of the CNTs in the coating was found to be highly advantageous, since the PIL bucky gel-coated fiber achieved the same extraction efficiency as the polydimethylsiloxane coating for four analytes. Much higher extraction efficiency was achieved for the rest of the analytes. This was attributed to $\pi-\pi$ interactions between the CNTs and the PAHs. Furthermore, the higher the quantity of the CNTs in the PIL bucky gel coating, the better the extraction efficiency. To elucidate the extraction mechanism (partition/adsorption) of the novel coating, extractions of various concentrations of 1-octanol, in the presence of naphthalene (an interfering compound), were conducted. The results indicated no competition between the two compounds, and therefore, a partition extraction mechanism (more preferable for complex matrices) was put forward. 
Table 2. Microextraction techniques employing CNT-IL composite nanomaterials.

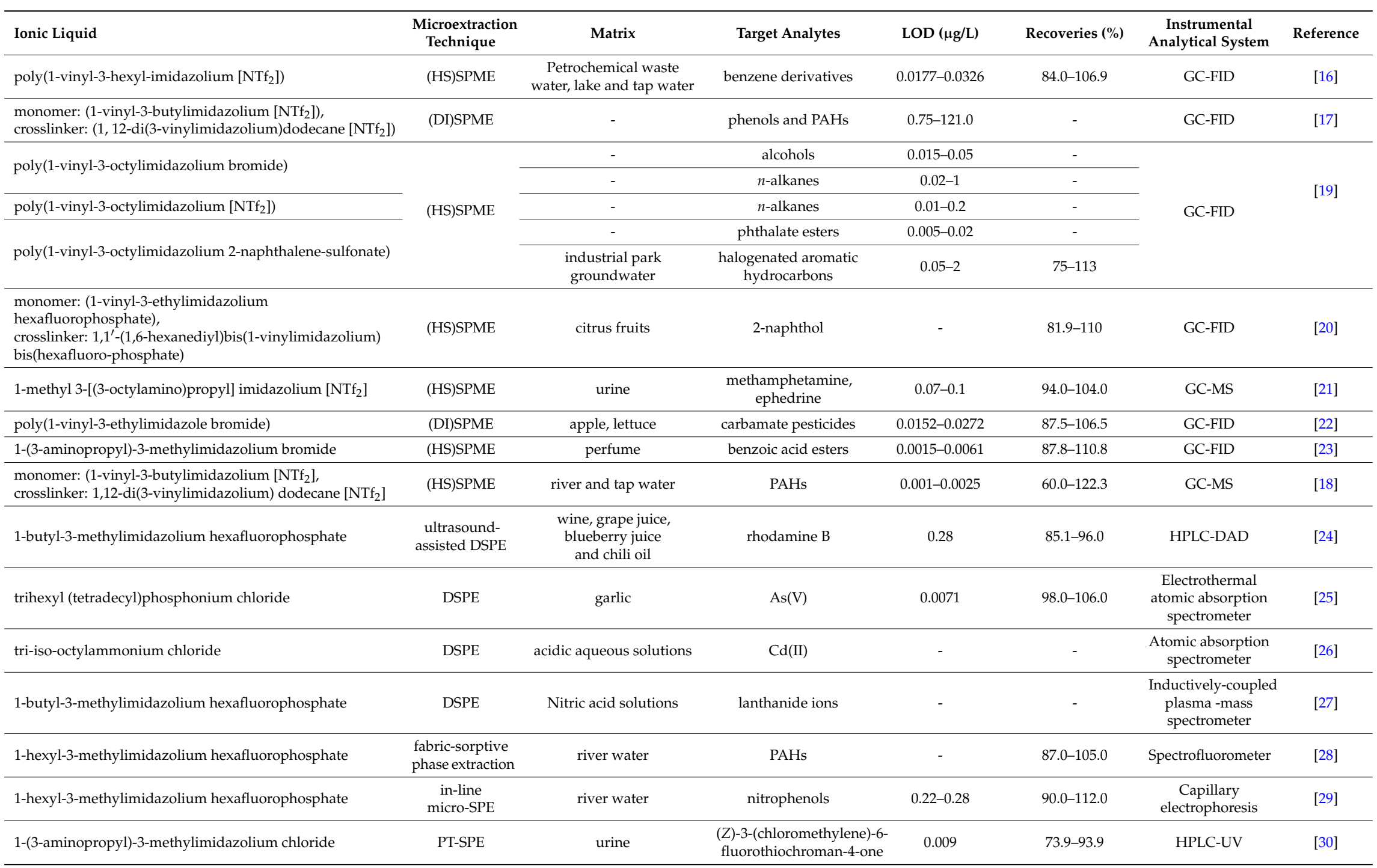


Despite the advantages that accompany the covalent PIL functionalization of CNTs, it has been stated that this functionalization has drawbacks, since it is time consuming and the chemical treatment employed can disrupt the $\pi$ conjugation of carbon nanotubes, causing destabilization of the structure, alteration of the electrical and mechanical properties, surface defects and shortening of the carbon nanotubes [16,31]. The non-covalent functionalization, based on van der Waals and electrostatic interactions, along with $\pi-\pi$ stacking has the merits of simplicity and versatility. Such an example is the case of the non-covalent coating of an SPME fiber with CNTs, functionalized with poly(1-vinyl-3-octylimidazolium bromide) [19]. The fabrication of the CNTs-PILs fiber is illustrated in Figure 2. The prepared fiber was initially used for the extraction of alcohols from aqueous matrixes. As the nature of the anion of the PIL alters the extraction properties of the fiber, an in situ, on-fiber anion exchange protocol was followed, instead of altering the anion of the PIL prior to the functionalization of the fiber. When bromide was substituted for $\left[\mathrm{NTf}_{2}\right]$, the coating was rendered more hydrophobic and, therefore, more suitable for $n$-alkanes. This was evidenced by relevant experiments assessing the performance of the two fibers (with bromide and $\left[\mathrm{NTf}_{2}\right]$ ) towards the extraction of $n$-alkanes. When the bromide anion was exchanged for 2-naphthalene-sulfonate, the interactions with aromatic compounds were favored, due to the $\pi-\pi, n-\pi$ and hydrophobic interactions that may occur. This was supported experimentally by the (HS)SPME of phthalate esters and halogenated aromatic hydrocarbons. From the three cases already mentioned, it is apparent that the composition of the IL is crucial, since the selection of the proper anion can tune the selectivity towards various chemical groups and assist the overall performance of the method, in terms of the achieved LODs and EFs.
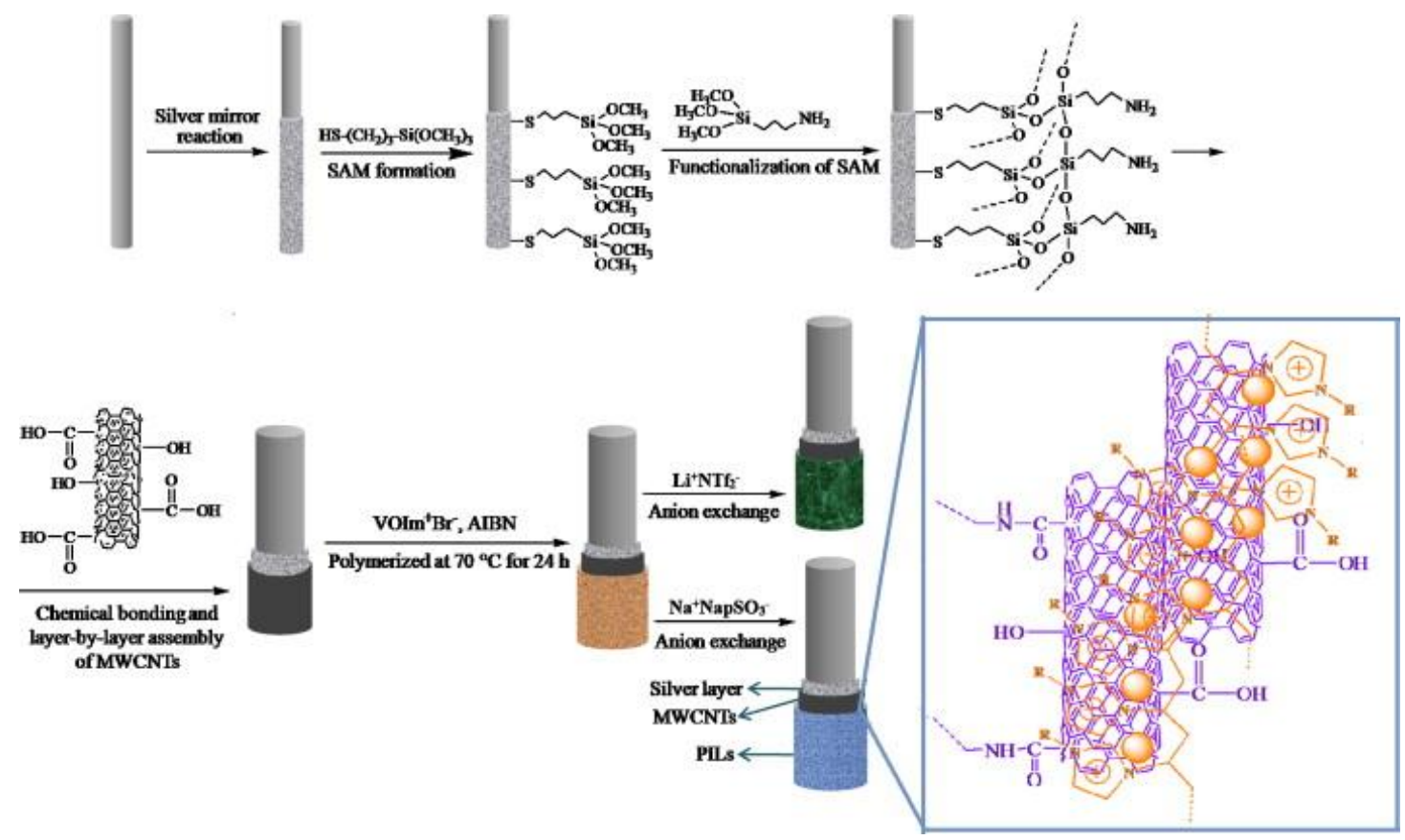

Figure 2. Preparation schema of the CNT-PILs SPME fiber. Reproduced with permission from [19]. Elsevier. Copyright Elsevier, 2015.

Another case of non-covalent coating of CNTs with IL is that presented by Feng et al. [20], who coated CNTs with 1-vinyl-3-ethylimidazolium hexafluorophosphate, after an in situ anion exchange. The coating of the CNTs with this IL facilitated the dispersibility of the CNTs in the pre-polymerization solution, which was used to fabricate a modified SPME fiber. Namely, the polymerization solution consisted of 1-vinyl-3-octylimidazolium bromide (IL monomer), pre-functionalized CNT-PIL, 1,1'-(1,6-hexanediyl)bis(1-vinylimidazolium) bis(hexafluoro-phosphate) (cross-linking agent) and azobisisobutyronitrile (initiator). The prepared fiber was used for the multiple (HS)SPME of 2-napthol 
from fruit samples, and the resulting method was found to be independent of matrix effects, although matrix variations were found to greatly influence the single (HS)SPME.

Taking advantage of the properties of other absorbing phases, synthesized in order to enhance the properties of the final material. Under this concept, two studies exploited the advantageous properties of nafion to prepare SPME fibers coated with nafion-CNT-PIL [21,22]. Narimani et al. firstly functionalized CNTs with amino groups to enhance the overall performance of the (HS)SPME fiber towards methamphetamine and ephenephrine [21]. Afterwards, the amino functionalized CNTs were coated with 1-methyl 3-[(3-octylamino)propyl] imidazolium [ $\left.\mathrm{NTf}_{2}\right]$. However, since the direct coating of the stainless steel fiber with the CNT-IL complex was not a successful choice due to the absence of binding between them, nafion was used as the first coating layer of the fiber, benefiting from its cation exchange properties. This way, the quantity of CNT-IL was increased, due to the electrostatic interactions between nafion and the IL. The proposed fiber was compared with fibers coated with the single components of the proposed composite material. The nafion-coated fiber, on its own, has low extraction ability despite being mechanically strong. The nafion-IL-coated fiber exhibited slightly better extraction ability compared to bare nafion coating, but bleeding of the IL during desorption was a serious defect. The nafion-CNT-coated fiber showed extraction ability between the two previous fibers. However, the authors found that prior functionalization of the CNTs could further enhance the extraction capability of the coating. The nafion-CNT-IL coating was nearly twice as efficient as the previous coatings. In another case presented by Wu et al., the role of nafion was to enhance the stability and durability of the coating [22]. The CNTs coated with poly(1-vinyl-3-ethylimidazole bromide) were mixed with 3,4-ethylenedioxythiophene (EDOT), and the mixture was electrodeposited on a stainless steel fiber leading to a PEDOT-PIL-CNT coating. Then, the coated fiber was immersed in a nafion solution to form an outer layer, and the modified fiber was used in a (DI)SPME procedure to extract carbamate pesticides from apple and lettuce. As reported, the fiber could be reused for more than 150 extractions without obvious loss of extraction efficiency. This was attributed to the nafion coating, since a fiber lacking the outer nafion coating could not be used more than 60 times.

Polyaniline (PANI) is another polymer with a porous structure and large specific area, but with low thermal stability, which is used for preparing composite coatings [23]. It was found that CNTs could enhance the physical-chemical properties of the polymer. Ai et al. proposed the coating of an SPME fiber with CNTs@IL (1-(3-aminopropyl)-3-methylimidazolium bromide), doped with PANI [23]. In order to achieve this, the fiber was immersed in a mixture of CNTs@IL and aniline, containing hexadecyl trimethyl ammonium bromide, and the CNTs@IL-polyaniline-doped coating was electrodeposited. PANI is a good electron donor, whereas the IL selected by the authors acts as an electron acceptor, facilitating the adsorption and immobilization of the CNTs@IL composite during the electropolymerization of aniline. The prepared fiber was tested for its extraction selectivity towards various groups of compounds, including: benzoic acid esters, amines, benzene compounds, alcohols, PAHs and phenolic compounds after (HS)SPME. In a similar way, Wu et al. synthesized a PANI-PIL-CNT composite, consisting of poly(1-vinyl-3-hexyl-imidazolium [NTf $\left.{ }_{2}\right]$ ) [16], where the PIL was used to enhance the dispersibility of the CNTs in water and organic solvents, as well as to prevent aggregation. The CNT-PIL composite was coated on a stainless steel fiber, which was firstly coated with PANI, via electrodeposition. The applicability of the prepared fiber to the (HS)SPME of compounds with varying polarity was tested. The fiber showed high affinity towards benzene derivatives, due to the simultaneous $\pi-\pi$ interactions, hydrogen bonding and the hydrophobic effect occurring between the extractant and the adsorbent. The proposed coated fiber was able to be used for 200 repeatable extractions without loss of the extraction performance.

\subsection{Dispersive Solid-Phase Microextraction}

So far, only a few cases of the utilization of CNT-IL composite materials in DSPE procedures have been reported in the literature, focusing mainly on the determination of metal species [24-27]. In three out of the four cases, the CNTs were coated with monomeric ILs following a straightforward synthetic 
route. Usually, an organic solvent is added to a mixture of CNT-IL to ensure the good dispersion of IL and the reproducibility of the synthesis [24]. Under this principle, functionalized CNTs with tri-iso-octylammonium bromide were used as an adsorbent for cadmium ions [26]. Unmodified CNTs were unable to extract cadmium ions, highlighting the necessity of the IL. Extraction of lanthanide ions, which is a rare case of target analytes, was the aim of the study of Bazhenov et al. [27]. The authors functionalized CNTs with 1-butyl-3-methylimidazolium hexafluorophosphate, following the aforementioned procedure. The images from scanning electron microscopy revealed that the IL did not only cover the CNTs from the outside, but also filled partially their inner cavities. The extraction of the lanthanide ions was performed with $0.1 \mathrm{M} \mathrm{HNO}_{3}$, in the presence of tetraphenyl methylene diphosphine dioxide. The bare CNTs were unable to extract any amount, while the addition of the IL greatly increased the extraction efficiency.

The last reported case focused on the determination of $\mathrm{As}(\mathrm{V})$ and $\mathrm{As}(\mathrm{III})$ in garlic samples [25]. The authors extracted arsenic from garlic with an acidic solution, and then, they added ammonium molybdate to form an arsenomolybdate complex. In this case, instead of directly using a CNT-IL composite material, the IL tetradecyl(trihexyl)phosphonium chloride was added to the extract to form a low-polarity complex with the arsenomolybdate, via the ion pair, followed by the addition of the CNTs. The whole composite material was directly inserted in a graphite furnace of an electrothermal atomic absorption spectrometer. This was attainable as CNTs are pyrolyzed prior to the atomization step, and therefore, no back-extraction/elution or digestion was needed. A drawback of the method was the potential interferences caused by phosphate anions during the step of arsenomolybdate complex formation. This hindrance was overcome by removing the phosphate anions with a mixture of organic solvents, prior to the addition of ammonium molybdate. The advantages of this approach were the low sample consumption ( $5 \mathrm{~mL}$ of the extract) and the low preconcentration/extraction time needed (20 $\mathrm{min}$ ) compared to previous methods.

\subsection{Other Microextraction Techniques}

CNT-IL composite materials were also employed for other microextraction procedures. The first of the reported cases focused on the fabric-sorptive phase extraction of PAHs from river water [28]. A cotton fiber with fixed dimensions was immersed in a bucky gel, prepared by mortar agitation, which consisted of CNTs and 1-hexyl-3-methylimidazolium hexafluorophosphate. The critical gel concentration of CNTs was found to be $0.5 \%-1 \%$. Excessive quantities of CNTs led to separation of the IL and gel phase, when centrifuged, demonstrating that a limited amount of IL could be trapped in the bucky gel. The next case of microextraction employing a CNT-IL composite is the study described by Polo-Luque et al. who aimed at the in-line preconcentration (in-tube SPME) of nitrophenols prior to capillary electrophoresis [29]. The preconcentration took place in the autosampler of the capillary electrophoresis, where a "spin-column" moved inside the sample vial. In the center of the moving part, there was a channel ( $1 \mathrm{~mm}$ in diameter and $4 \mathrm{~mm}$ in length), through which the sample was circulated. The adsorbent material was laid on the channel walls, and by applying mechanical pressure, the liquid sample was forced to pass through the channel, leading to the analyte extraction. The velocity towards the bottom of the vial and the rotating speed directly affected the preconcentration rate of the analytes, as well as the reproducibility. With the proposed method, $400-600 \mu \mathrm{L}$ of sample could pass through the extraction unit, in $5 \mathrm{~min}$. After the completion of extraction, the sample was rejected and an elution solvent passed through the channel in order to elute the adsorbed compounds, prior to the capillary electrophoresis. Good reproducibility, good analytical performance, low cost and automation are the main advantages of this microextraction technique.

Chen et al. developed and used an IL-G-CNT composite as an adsorbent in a PT-SPE procedure. The combination of IL, G and CNTs yielded satisfactory extraction of thiochromanones, which was much less effective in the absence of any of the above components. The results are undoubtedly better than those with G-CNTs, since the IL enables the ion exchange and electrostatic interactions of the analytes with the adsorbent, instead of only the $\pi-\pi$ interactions occurring in the case of G-CNTs [30]. 


\section{Ionic Liquid-Coated Magnetic Graphene-Based Nanomaterials}

\subsection{Magnetic Dispersive Solid-Phase Extraction}

Despite the progress in developing G/GO and CNTs materials modified with various ILs, it is obvious from the above discussion and Figure 1 that novel extraction procedures based on the principle of SPME hold the largest share among the microextraction procedures. This can be partially justified by the limited potential that composite materials containing GO have, as regards their applicability to DSPE methods, due to their high dispersibility, as a result of the high hydrophilicity of GO [32]. On the contrary, the low dispersibility of $G$ in water minimizes the adsorption potential of the material. To overcome these hindrances, magnetic nanoparticles were embodied in the composite materials to convert them into being magnetic, thus enabling easier isolation from the matrix or increasing the wettability of graphene-based materials [33]. The magnetic materials can be employed to develop MSPE methods, under the principles of microextraction, which possess advantages over magnetic G/GO-based MSPE methods. The main advantage of the MSPE methods over the conventional DSPE is the shorter time needed for the sample preparation, since time-consuming steps, like filtration/centrifugation, are omitted.

Hitherto, miscellaneous IL-coated, magnetic graphene-based materials have been synthesized (Table 3). Almost exclusively, magnetite $\left(\mathrm{Fe}_{3} \mathrm{O}_{4}\right)$ was used to endow nanomaterials with magnetic properties, although, virtually, other iron oxides are present. In most cases, magnetite nanoparticles were coated with silica, to form core-shell magnetic nanoparticles, which are less prone to oxidation compared to magnetite. The next step consisted of the reaction with an amino-terminated silane, so that free amino groups are formed on the surface of the silica-coated magnetite nanospheres. Through the free amino groups, GO was chemically bonded to form a $\mathrm{Fe}_{3} \mathrm{O}_{4} @ \mathrm{SiO}_{2}-\mathrm{NH}_{2} @ G \mathrm{GO}$ composite. The next step was the reduction of GO to G, often with hydrazine. However, this step was optional and hinges on two factors: (i) the ease of synthetic route to modify the $G$ or the GO with the desirable IL; depending on the functional groups exploited and the method employed, the best option is selected; (ii) since the material is going to be used as an adsorbent, the affinity of the analytes with the G or the GO, shall be considered. According to this common procedure, $\mathrm{Fe}_{3} \mathrm{O}_{4} @ \mathrm{SiO}_{2}-\mathrm{NH}_{2} @ \mathrm{GO} @ \mathrm{IL}$ composite nanomaterials were obtained, with enhanced properties. Up to now, two studies based on this procedure synthesized the described composite materials with varying IL coatings: (i) Cai et al. prepared the $\mathrm{Fe}_{3} \mathrm{O}_{4} @ \mathrm{SiO}_{2}-\mathrm{NH}_{2} @ G O$ composite and coated it with 1-carboxymethyl-3-methylimidazolium chloride [34] for the determination of chlorophenols; and (ii) Huang et al. synthesized the above-mentioned composite material, omitting the formation of silica on the surface or magnetite nanoparticles [35]. Following functionalization with a betaine-based IL, the nanomaterial was successfully applied to the MPSE of bovine serum albumin from bovine calf whole blood. 
Table 3. Microextraction techniques employing magnetic G-IL composite nanomaterials.

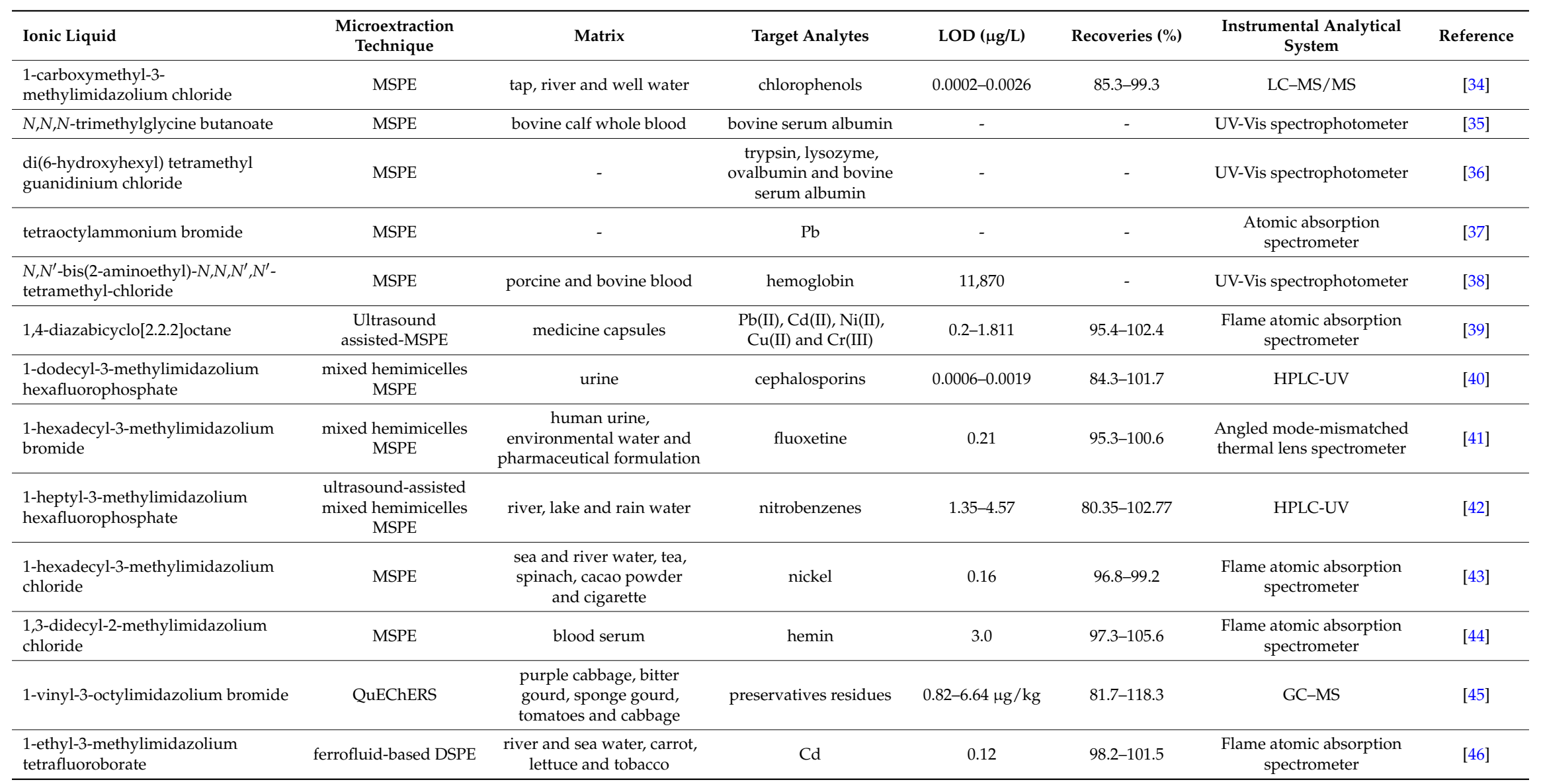


Chitosan, a polysaccharide polymer bearing hydroxyl and amino groups, may be a judicious alternative to the silica coating of the magnetite nanoparticles. It can easily coat magnetite nanoparticles, as well as form bonds with GO via amine-carboxyl groups bonding. Two research groups have synthesized $\mathrm{Fe}_{3} \mathrm{O}_{4} @$ chitosan@GO@IL composites with different ILs, for the MSPE of different analytes. In the first case, the IL used was di(6-hydroxyhexyl) tetramethyl guanidinium-chloride, and the composite material was suitable for the extraction of trypsin, lysozyme, ovalbumin and bovine serum albumin [36]. In the second case, the magnetic GO was functionalized with tetraoctylammonium bromide, and the material was found suitable for the MSPE of Pb [37].

Finally, in an effort to synthesize functional adsorbent materials, there are some reported cases that diverge from the above procedures. Wen et al. chose to use nano-iron, covered with polyethylene glycol-4000, instead of magnetite [38]. The vibrating sample magnetometer curves demonstrated that the produced Fe@GO@IL complex demonstrates satisfactory saturation magnetization values, enabling its use in MSPE procedures. Wen et al. used an amino functional dicationic IL ( $N, N^{\prime}$-bis(2-aminoethyl)- $N, N, N^{\prime}, N^{\prime}$-tetramethyl-chloride) as a coating to the magnetic GO, and the whole adsorbent was used to develop a method for the determination of hemoglobin [38]. When compared to other IL coatings with fewer amino-functional groups or a shorter alkyl chain, the extraction capability of the material was reduced. Therefore, the presence of the amino functional groups promotes the hydrogen bonding interactions between the adsorbent and hemoglobin. The last case revolves around the use of a double-charged IL immobilized on a magnetic GO complex [39]. A magnetite-grafted GO was modified with (3-mercaptopropyl)trimethoxysilane, and finally, diazoniabicyclo[2.2.2]octane chloride was attached covalently for the ultrasound-assisted MSPE of heavy metals. Due to the double-charged IL used, the adsorbent shows high adsorption capacity. The amount of sorbent used for the extraction of five heavy metals is nearly five-times lower than that of other methods.

\subsection{Other Microextraction Techniques}

Another mode of microextraction, which makes use of the magnetic properties of the adsorbent nanoparticles, is the mixed hemimicelles-MSPE. In this technique, mixed hemimicelles (hemimicelles and admicelles) of the IL are formed on the surface of the magnetic G/GO, using a proper IL-based surfactant. Hitherto, a few studies have been published relying on the above-mentioned principle. The first study focused on the extraction of cephalosporins from urine, using 1-dodecyl-3-methylimidazolium hexafluorophosphate to form the mixed hemimicelles [40]. The new method shows high extractability, a relatively wide linear range and satisfactory analytical figures of merit. The method developed by Kazemi et al. for the extraction of fluoxetine from environmental, biological and pharmaceutical samples proved highly time saving, since the overall procedure is completed in less than $15 \mathrm{~min}$ [41]. A small amount of magnetic graphene modified with 1-hexadecyl-3-methylimidazolium bromide was used, due to the high capacity of the material, rendering the method cost-effective. Similar merits were noticed in the method developed by Cao et al. for the determination of nitrobenzenes in environmental samples, based on $\mathrm{Fe}_{3} \mathrm{O}_{4} @$ graphene coated with 1-heptyl-3-methylimidazolium hexafluorophosphate [42]. The developed method uses an infinitesimal amount of extraction solvent and small sample volumes. The study of Aliyari et al. revolved around the in situ synthesis of magnetite, based on the chemical co-precipitation of $\mathrm{Fe}^{3+}$, directly on the surface of GO, prior to the modification with mixed IL hemimicelles [43]. Based on an electrostatic self-assembly technique, 1-hexadecyl-3-methylimidazolium chloride adhered on the $\mathrm{GO}$, forming hemimicelles/admicelles through electrostatic attraction of the negative surface charge of the GO and the cationic IL. The long alkyl chain of the IL facilitated the assembly due to the hydrophobic interactions. Taking advantage of its property to solubilize organic molecules, a hybrid nanocomposite material with dimethylglyoxime was produced and used as an adsorbent for traces of nickel, for a wide variety of matrices. Under the same synthetic principle, Farzin et al. formed mixed hemimicelles, by way of 1,3-didecyl-2-methylimidazolium chloride, on the surface of magnetic GO, 
facilitating the fast MSPE of hemin from blood serum [44]. The developed technique was compared with a commercially available hemin assay kit. The results obtained were not statistically different, suggesting that the proposed method is a reliable and promising alternative to the determination of hemin.

The applicability of the magnetic G-IL composites in microextraction techniques is broad, as revealed by the discussion above. However, there are two studies that make use of composite magnetic nanomaterials and that deserve consideration, because of their potential for alternative microextraction purposes. In the first case, Chen et al. synthesized the $\mathrm{Fe}_{3} \mathrm{O}_{4} @ \mathrm{SiO}_{2}-\mathrm{NH}_{2} @ \mathrm{G}$ composite [45]. Then, they added 1-vinyltriethoxysilane on the surface of the composite, via hydrogen bonds, and finally, they added 1-vinyl-3-octylimidazolium bromide to obtain a PIL coating. The magnetic adsorbent was used in the clean-up step of a Quick, Easy, Cheap, Effective, Rugged and Safe (QuEChERS) method to purify the extract obtained from vegetables, in order to determine their content in preservative residues. The developed method can simultaneously extract twenty preservatives, twice more than the number of analytes of previously developed methods, which also make use of magnetic nanoparticles. In another study, instead of using a solid adsorbent, the authors developed a method based on the principle of DSPE, using a ferrofluid, which was synthesized using a $\mathrm{Fe}_{3} \mathrm{O}_{4} @ \mathrm{GO} @ \mathrm{IL}$ complex and 1-ethyl-3-methylimidazolium tetrafluoroborate as IL [46]. As evidenced by the authors, the type of the IL is important for the ferrofluid in order to prevent aggregation and sedimentation. The resulting ferrofluid is stable, with high water dispersibility, thus facilitating its use for microextraction purposes. The IL, in the last case, is exclusively used as the carrier fluid without any profound role in the extraction process, in contrast with the IL mixed hemimicelles formed on a solid surface, which are predominantly used for extraction purposes.

\section{Ionic Liquid Coated Magnetic CNTs-Based Materials}

\subsection{Magnetic Solid-Phase Extraction MSPE}

Till now, a limited number of studies have been conducted, with respect to the synthesis and employment of magnetic CNTs-IL composites in analytical procedures (Table 4) [47-52]. In the studies examined, CNTs were magnetized before or after their modification with IL, either synthesizing magnetite nanoparticles directly on the surface of acid-treated CNTs or spontaneously bonding them with the CNT-IL composite. In one of them, unlike all previous synthetic routes, the authors synthesized stepwise the IL on the CNTs, instead of covalently or non-covalently functionalizing them with the IL. A necessary step was the functionalization of the CNTs with acid chloride functional groups, through the reaction with thionyl chloride. Afterwards, 1-(3-aminopropyl)imidazole was chemically bonded on the functionalized CNTs, and 1-chlorobutane [47] or 1-bromobutane [48] was added to complete the synthesis. The composites were used in MSPE procedures of triazole fungicides [47] and aryloxyphenoxy-propionate herbicides (and their metabolites) [48] from environmental water samples, after they had been converted into being magnetic. Both extraction procedures were fast ( 5 and $8 \mathrm{~min}$ ) and used small amounts of sorbent materials ( 2 and $12.5 \mathrm{mg}$ ). As a result of the presence of the IL, the two methods achieved LODs ranging between 0.05 and $0.2 \mathrm{ng} \cdot \mathrm{mL}^{-1}$ for triazole fungicides and $0.002-3.4 \mathrm{mg} \cdot \mathrm{L}^{-1}$ for aryloxyphenoxy-propionate herbicides. The recoveries achieved were different, despite the similarity of the adsorbent material $(84.7 \%-105.3 \%$ for triazole fungicides and $66.1 \%-89.6 \%$ for aryloxyphenoxy-propionate herbicides). 
Table 4. Microextraction techniques employing magnetic CNT-IL composite nanomaterials.

\begin{tabular}{|c|c|c|c|c|c|c|c|}
\hline Ionic Liquid & $\begin{array}{l}\text { Microextraction } \\
\text { Technique }\end{array}$ & Matrix & Target Analytes & $\operatorname{LOD}(\mu \mathrm{g} / \mathrm{L})$ & Recoveries (\%) & $\begin{array}{l}\text { Instrumental Analytical } \\
\text { System }\end{array}$ & Reference \\
\hline 1-butyl-3-aminopropyl imidazolium chloride & MSPE & canal water & triazole fungicides & $0.05-0.22$ & $84.7-105.3$ & GC-MS & [47] \\
\hline \multirow{2}{*}{ 1-butyl-3-aminopropyl imidazolium bromide } & \multirow{2}{*}{ MSPE } & \multirow{2}{*}{$\begin{array}{l}\text { ground and } \\
\text { reservoir water }\end{array}$} & \multirow{2}{*}{$\begin{array}{l}\text { aryloxyphenoxy- } \\
\text { propionate herbicides }\end{array}$} & $2.8-14.3$ & \multirow{2}{*}{$66.1-89.6$} & HPLC-DAD & \multirow{2}{*}{ [48] } \\
\hline & & & & $0.002-3.4$ & & HPLC-MS/MS & \\
\hline $\begin{array}{l}\text { 1-(4-vinylbenzyl)-(3-aminopropyl)- } \\
\text { imidazolium chloride }\end{array}$ & MSPE & porcine whole blood & $\mathrm{Cu}, \mathrm{Zn}$-superoxide & - & $82.7-102.3$ & UV-Vis spectrophotometer & [49] \\
\hline $\begin{array}{l}\text { 6-hydroxy- } \mathrm{N} \text {-(2-hydroxyethyl)- } \mathrm{N}, \mathrm{N}- \\
\text { dimethylhexan-1-aminium chloride }\end{array}$ & MSPE & - & lysozyme & - & - & UV-Vis Spectrophotometer & {$[50]$} \\
\hline 1-hexadecyl-3-methyl-imidazolium bromide & $\begin{array}{l}\text { mixed hemimicelles } \\
\text { MSPE }\end{array}$ & human urine & flavonoids & $0.20-0.75$ & $90.1-97.6$ & HPLC-UV & {$[51]$} \\
\hline $\begin{array}{l}\text { 1-butyl-3-methylimidazolium } \\
\text { hexafluorophosphate }\end{array}$ & USA-IL-LDMME & $\begin{array}{l}\text { tap and well water, } \\
\text { cow milk, fish liver }\end{array}$ & Cd, As & $0.003-0.005$ & $94.6-98.0$ & $\begin{array}{l}\text { Atomic absorption } \\
\text { spectrometer }\end{array}$ & [52] \\
\hline
\end{tabular}


In the study of Wen et al., a magnetic CNTs-PIL composite was used to extract $\mathrm{Cu}$, Zn-superoxide dismutase from porcine whole blood [49]. The composite material was proven to be superior compared to magnetic CNT-IL composite and magnetic CNTs, in terms of extraction capacity for $\mathrm{Cu}, \mathrm{Zn}$-superoxide dismutase, which was three-times higher than that of the two latter materials. Additionally, the adsorbent showed lower affinity towards lysozyme and bovine hemoglobin, the two major components of the studied matrix. The proposed mechanism of interaction between adsorbent and analyte included hydrogen bonding, $\pi-\pi$ and electrostatic interactions. It is noteworthy that instead of organic solvents, a solution of sodium chloride was used for the elution of $\mathrm{Cu}, \mathrm{Zn}$-superoxide dismutase from the adsorbent. The efficient desorption was attributed to the weakening of the electrostatic interactions between the analyte and the adsorbent. In the last example, CNTs were rendered magnetic by synthesizing magnetite nanoparticles on the surface, then coating them with silicon dioxide. A dual hydroxyl IL (6-hydroxy- $N$-(2-hydroxyethyl)- $N, N$-dimethylhexan-1-aminium chloride) was synthesized on the surface, resulting in an IL-CNTs@ $\mathrm{Fe}_{3} \mathrm{O}_{4} @ \mathrm{SiO}_{2}$ composite material [50]. The synthesized material was tested for the extraction capability of four different proteins: bovine serum albumin, lysozyme, trypsin and ovalbumin. Lysozyme was extracted more easily. The proposed adsorbent was superior to magnetic $\mathrm{CNTs}-\mathrm{SiO}_{2}$ because of the electrostatic and hydrophobic interactions between lysozyme and the IL. Additionally, the contribution of the two hydroxyl groups on the surface of the IL was examined by comparing with the respective adsorbent, without hydroxyl groups. The dual hydroxyl-functionalized IL was preferable, since it enhanced the extraction capability by forming hydrogen bond interactions with the aliphatic carbon residue of the lysozyme. Overall, the DSPE procedures carried out with the CNT-IL composite were endowed with excellent repeatability, high recoveries and specificity.

\subsection{Other Microextraction Techniques}

Xiao et al. reported on the extraction of PAHs from urine samples using magnetic CNTs and 1-hexadecyl-3-methylmidazolium bromide, in a mixed hemimicelles MSPE procedure [51]. Figure 3 illustrates the whole procedure of the preparation of surfactant-coated CNTs and the application to simultaneous microextraction and preconcentration of analytes. In the beginning, the IL was mixed with the magnetic CNTs via ultrasonication, so that mixed hemimicelles were formed on the surface of the magnetic CNTs. Subsequently, the urine sample was added and the mixture was further sonicated to disperse the adsorbent material and extract the analytes. The adsorbent was compared with IL-coated $\mathrm{Fe}_{3} \mathrm{O}_{4} @ \mathrm{SiO}_{2}$ nanoparticles; it was found that at low concentrations of analytes $(<40 \mathrm{ng} / \mathrm{mL})$, the recoveries of the two materials were the same, while for higher concentrations, the adsorbent containing the CNTs was more efficient. This was attributed to the great number of hemimicelles formed on the surface of each material. Therefore, the CNTs enhance the extraction mainly indirectly, by increasing the amount of hemimicelles available for the extraction. The analytical characteristics of the proposed method were quite acceptable, and the proposed method is highly time saving, low cost and environmentally friendly, since small amounts of organic solvent are used for the elution, while the adsorbent could be used for more than one extraction-desorption cycle. The last reported case deals with the extraction of $\mathrm{Cd}$ and As from water, milk and fish liver samples [52]. In this case, sodium diethyldithiocarbamate trihydrate was added to the prepared sample, functioning as a chelating agent, and then, 1-butyl-3-methylimidazolium hexafluorophosphate was added. The mixture was ultrasonicated, and then, the magnetic CNTs were added, followed by another short ultrasonication period. The magnetic particles were harvested with the aid of a magnet, and then, the metal-diethyldithiocarbamate complex was eluted from the adsorbent. In this case (termed ultrasound-assisted, ionic liquid-linked, dual-magnetic multi-walled carbon nanotube microextraction (USA-IL-LDMME), by the authors), the IL functions as the main extraction solvent, while magnetic CNTs are used to increase the extraction efficiency and to couple with the IL, facilitating the easier separation of the IL from the solution. 


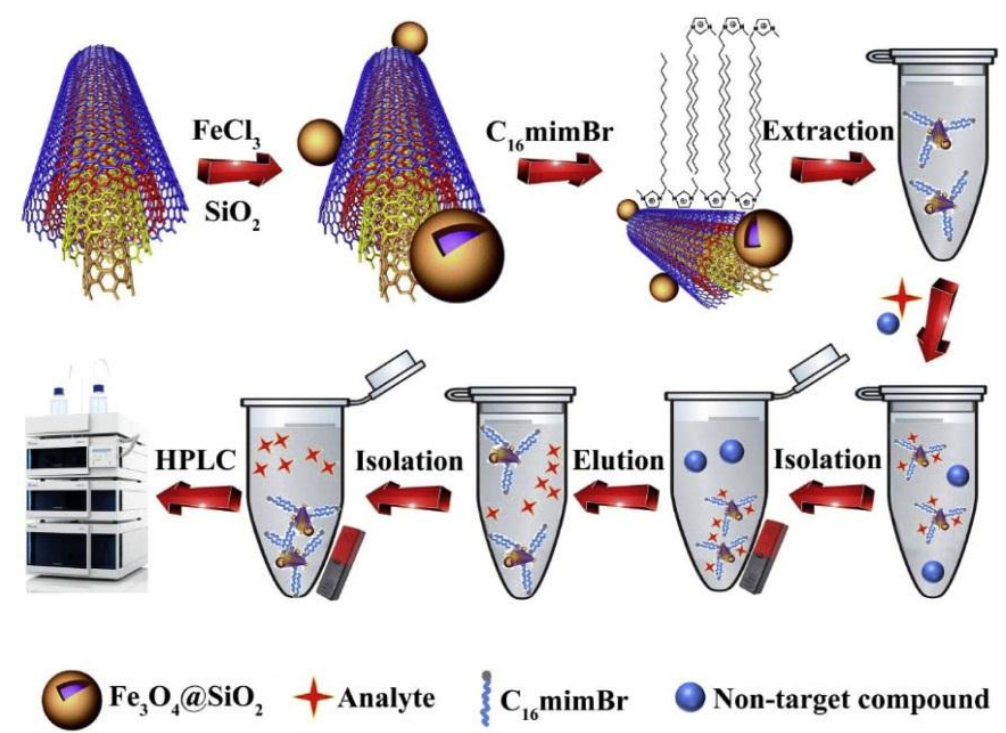

Figure 3. Preparation of surfactant-coated magnetic CNTs and the application to microextraction and preconcentration of analytes. Reproduced with permission from [51]. Copyright Elsevier, 2014.

\section{Conclusions and Perspectives}

Here, we have discussed a variety of IL-functionalized carbon-based materials, consisting predominantly of graphene and multi-walled carbon nanotubes, for microextraction purposes, and we have highlighted the emerging frontiers of this aspect of nanoscience and analytical chemistry. Increasing extraction yield, selectivity and sensitive detection are the most exciting and challenging aspects of this field.

Graphene-IL and CNT-IL hybrid materials have been synthesized and used as sorbents in microextraction procedures for various classes of organic compounds and metals in food and water samples. These materials proved to be advantageous and more efficient than bare graphene, CNTs or IL, underlining their combined capability via various interactions. Furthermore, it is noteworthy that the composite material can adsorb various classes of compounds by altering the anion of the IL, which is an elegant way to tune selectivity and applicability. Despite their successful synthesis and employment in microextraction, composite materials endowed with magnetic properties and outstanding characteristics were also synthesized.

Carbon-based nanomaterials, coated with IL, clearly contribute significantly towards the development of enhanced analytical methods due to their increased efficiency, recovery and selectivity, as adsorbents. Furthermore, in some cases, they proved to surpass commercially available sorbent materials, employed in microextraction procedures. In the future, large-scale synthesis of the materials should be examined, in order to use them as reliable commercial materials for microextraction purposes. Moreover, more research should be conducted focusing on other matrices or classes of compounds that can be extracted by the hybrid adsorbents. As "nanoparticles will be part of the heart and soul of analytical chemistry", the applications of composite nanomaterials, based on carbon structure-IL, in sample preparation, will continue to improve, and new analytical applications for the composite materials are expected to emerge, since their full potential is yet to be realized.

Conflicts of Interest: The authors report no conflict of interest. 


\section{Abbreviations}

$\begin{array}{ll}\text { CNTs } & \text { carbon nanotubes } \\ \text { DI } & \text { direct-immersion } \\ \text { DSPE } & \text { dispersive solid-phase microextraction } \\ \text { EDOT } & \text { 3,4-ethylenedioxythiophene } \\ \text { EFs } & \text { enrichment factors } \\ \text { G } & \text { graphene } \\ \text { GO } & \text { graphene oxide } \\ \text { HS } & \text { headspace } \\ \text { IL } & \text { Ionic liquids } \\ \text { LODs } & \text { limits of detection } \\ \text { MSPE } & \text { magnetic solid-phase extraction } \\ \left.\text { [NTf }{ }_{2}\right] & \text { bis(trifluoromethanesulfonyl imide) } \\ \text { PAHs } & \text { polycyclic aromatic hydrocarbons } \\ \text { PANI } & \text { polyaniline } \\ \text { PEDOT } & \text { poly(3,4-ethylenedioxythiophene) } \\ \text { PILs } & \text { polymeric ionic liquids } \\ \text { PT-SPE } & \text { pipette-tip solid-phase extraction } \\ \text { QuEChERS } & \text { Quick, Easy, Cheap, Effective, Rugged and Safe } \\ \text { SPE } & \text { solid-phase extraction } \\ \text { SPME } & \text { solid-phase microextraction } \\ \text { USA-IL-LDMME } & \text { ultrasound-assisted, ionic liquid-linked, dual-magnetic multi-walled carbon } \\ & \text { nanotube microextraction }\end{array}$

\section{References}

1. Stalikas, C.D.; Fiamegos, Y.C. Microextraction combined with derivatization. TrAC Trends Anal. Chem. 2008, 27, 533-542. [CrossRef]

2. Zhang, B.-T.; Zheng, X.; Li, H.-F.; Lin, J.-M. Application of carbon-based nanomaterials in sample preparation: A review. Anal. Chim. Acta 2013, 784, 1-17. [CrossRef] [PubMed]

3. Iijima, S. Helical microtubules of graphitic carbon. Nature 1991, 354, 56-58. [CrossRef]

4. Herrero Latorre, C.; Álvarez Méndez, J.; Barciela García, J.; García Martín, S.; Peña Crecente, R.M. Carbon nanotubes as solid-phase extraction sorbents prior to atomic spectrometric determination of metal species: A review. Anal. Chim. Acta 2012, 749, 16-35. [CrossRef] [PubMed]

5. Speltini, A.; Merli, D.; Profumo, A. Analytical application of carbon nanotubes, fullerenes and nanodiamonds in nanomaterials-based chromatographic stationary phases: A review. Anal. Chim. Acta 2013, 783, 1-16. [CrossRef] [PubMed]

6. Chen, D.; Feng, H.; Li, J. Graphene oxide: Preparation, functionalization, and electrochemical applications. Chem. Rev. 2012, 112, 6027-6053. [CrossRef] [PubMed]

7. Han, D.; Row, K.H. Recent applications of ionic liquids in separation technology. Molecules 2010, 15, 2405. [CrossRef] [PubMed]

8. Wasserscheid, P.; Welton, T. Ionic Liquids in Synthesis, 2nd ed.; Wiley-VCH: Berlin, Germany, 2003.

9. Vidal, L.; Riekkola, M.-L.; Canals, A. Ionic liquid-modified materials for solid-phase extraction and separation: A review. Anal. Chim. Acta 2012, 715, 19-41. [CrossRef] [PubMed]

10. Hou, X.; Guo, Y.; Liang, X.; Wang, X.; Wang, L.; Wang, L.; Liu, X. Bis(trifluoromethanesulfonyl)imide-based ionic liquids grafted on graphene oxide-coated solid-phase microextraction fiber for extraction and enrichment of polycyclic aromatic hydrocarbons in potatoes and phthalate esters in food-wrap. Talanta 2016, 153, 392-400. [CrossRef] [PubMed]

11. Sun, M.; Feng, J.; Bu, Y.; Duan, H.; Wang, X.; Luo, C. Development of a solid-phase microextraction fiber by the chemical binding of graphene oxide on a silver-coated stainless-steel wire with an ionic liquid as the crosslinking agent. J. Sep. Sci. 2014, 37, 3691-3698. [CrossRef] [PubMed] 
12. Wu, M.; Ai, Y.; Zeng, B.; Zhao, F. In situ solvothermal growth of metal-organic framework-ionic liquid functionalized graphene nanocomposite for highly efficient enrichment of chloramphenicol and thiamphenicol. J. Chromatogr. A 2016, 1427, 1-7. [CrossRef] [PubMed]

13. Sun, M.; Bu, Y.; Feng, J.; Luo, C. Graphene oxide reinforced polymeric ionic liquid monolith solid-phase microextraction sorbent for high-performance liquid chromatography analysis of phenolic compounds in aqueous environmental samples. J. Sep. Sci. 2016, 39, 375-382. [CrossRef] [PubMed]

14. Wu, M.; Wang, L.; Zeng, B.; Zhao, F. Fabrication of poly(3,4-ethylenedioxythiophene)-ionic liquid functionalized graphene nanosheets composite coating for headspace solid-phase microextraction of benzene derivatives. J. Chromatogr. A 2014, 1364, 45-52. [CrossRef] [PubMed]

15. Serrano, M.; Chatzimitakos, T.; Gallego, M.; Stalikas, C.D. 1-butyl-3-aminopropyl imidazoliumfunctionalized graphene oxide as a nanoadsorbent for the simultaneous extraction of steroids and $\beta$-blockers via dispersive solid-phase microextraction. J. Chromatogr. A 2016, 1436, 9-18. [CrossRef] [PubMed]

16. Wu, M.; Wang, L.; Zhao, F.; Zeng, B. Ionic liquid polymer functionalized carbon nanotubes-coated polyaniline for the solid-phase microextraction of benzene derivatives. RSC Adv. 2015, 5, 99483-99490. [CrossRef]

17. Cordero-Vaca, M.; Trujillo-Rodríguez, M.J.; Zhang, C.; Pino, V.; Anderson, J.L.; Afonso, A.M. Automated direct-immersion solid-phase microextraction using crosslinked polymeric ionic liquid sorbent coatings for the determination of water pollutants by gas chromatography. Anal. Bioanal. Chem. 2015, 407, 4615-4627. [CrossRef] [PubMed]

18. Zhang, C.; Anderson, J.L. Polymeric ionic liquid bucky gels as sorbent coatings for solid-phase microextraction. J. Chromatogr. A 2014, 1344, 15-22. [CrossRef] [PubMed]

19. Feng, J.; Sun, M.; Bu, Y.; Luo, C. Facile modification of multi-walled carbon nanotubes-polymeric ionic liquids-coated solid-phase microextraction fibers by on-fiber anion exchange. J. Chromatogr. A 2015, 1393, 8-17. [CrossRef] [PubMed]

20. Feng, J.; Sun, M.; Li, L.; Wang, X.; Duan, H.; Luo, C. Multiwalled carbon nanotubes-doped polymeric ionic liquids coating for multiple headspace solid-phase microextraction. Talanta 2014, 123, 18-24. [CrossRef] [PubMed]

21. Narimani, O.; Dalali, N.; Rostamizadeh, K. Functionalized carbon nanotube/ionic liquid-coated wire as a new fiber assembly for determination of methamphetamine and ephedrine by gas chromatography-mass spectrometry. Anal. Methods 2014, 6, 8645-8653. [CrossRef]

22. Wu, M.; Wang, L.; Zeng, B.; Zhao, F. Ionic liquid polymer functionalized carbon nanotubes-doped poly(3,4-ethylenedioxythiophene) for highly-efficient solid-phase microextraction of carbamate pesticides. J. Chromatogr. A 2016, 1444, 42-49. [CrossRef] [PubMed]

23. Ai, Y.; Wu, M.; Li, L.; Zhao, F.; Zeng, B. Highly selective and effective solid phase microextraction of benzoic acid esters using ionic liquid functionalized multiwalled carbon nanotubes-doped polyaniline coating. J. Chromatogr. A 2016, 1437, 1-7. [CrossRef] [PubMed]

24. Xu, X.; Zhang, M.; Wang, L.; Zhang, S.; Liu, M.; Long, N.; Qi, X.; Cui, Z.; Zhang, L. Determination of rhodamine $\mathrm{b}$ in food using ionic liquid-coated multiwalled carbon nanotube-based ultrasound-assisted dispersive solid-phase microextraction followed by high-performance liquid chromatography. Food Anal. Methods 2016, 9, 1696-1705. [CrossRef]

25. Grijalba, A.C.; Escudero, L.B.; Wuilloud, R.G. Ionic liquid-assisted multiwalled carbon nanotube-dispersive micro-solid phase extraction for sensitive determination of inorganic as species in garlic samples by electrothermal atomic absorption spectrometry. Spectrochim. Acta Part B 2015, 110, 118-123. [CrossRef]

26. Alguacil, F.J.; García-Díaz, I.; López, F.A.; Rodríguez, O. Liquid-liquid extraction of cadmium(ii) by tioacl (tri-iso-octylammonium chloride) ionic liquid and its application to a tioacl impregnated carbon nanotubes system. Rev. Met. 2015, 51. [CrossRef]

27. Bazhenov, A.V.; Fursova, T.N.; Turanov, A.N.; Aronin, A.S.; Karandashev, V.K. Properties of a composite material based on multi-walled carbon nanotubes and an ionic liquid. Phys. Solid State 2014, 56, 572-579. [CrossRef]

28. Polo-Luque, M.L.; Simonet, B.M.; Valcárcel, M. Ionic liquid combined with carbon nanotubes: A soft material for the preconcentration of pahs. Talanta 2013, 104, 169-172. [CrossRef] [PubMed]

29. Polo-Luque, M.L.; Simonet, B.M.; Valcárcel, M. Solid-phase extraction of nitrophenols in water by using a combination of carbon nanotubes with an ionic liquid coupled in-line to ce. Electrophoresis 2013, 34, 304-308. [CrossRef] [PubMed] 
30. Chen, H.; Yuan, Y.; Xiang, C.; Yan, H.; Han, Y.; Qiao, F. Graphene/multi-walled carbon nanotubes functionalized with an amine-terminated ionic liquid for determination of (z)-3-(chloromethylene)-6fluorothiochroman-4-one in urine. J. Chromatogr. A 2016, 1474, 23-31. [CrossRef] [PubMed]

31. Tunckol, M.; Fantini, S.; Malbosc, F.; Durand, J.; Serp, P. Effect of the synthetic strategy on the non-covalent functionalization of multi-walled carbon nanotubes with polymerized ionic liquids. Carbon 2013, 57, $209-216$. [CrossRef]

32. Stankovich, S.; Dikin, D.A.; Piner, R.D.; Kohlhaas, K.A.; Kleinhammes, A.; Jia, Y.; Wu, Y.; Nguyen, S.T.; Ruoff, R.S. Synthesis of graphene-based nanosheets via chemical reduction of exfoliated graphite oxide. Carbon 2007, 45, 1558-1565. [CrossRef]

33. Maidatsi, K.V.; Chatzimitakos, T.G.; Sakkas, V.A.; Stalikas, C.D. Octyl-modified magnetic graphene as a sorbent for the extraction and simultaneous determination of fragrance allergens, musks, and phthalates in aqueous samples by gas chromatography with mass spectrometry. J. Sep. Sci. 2015, 38, 3758-3765. [CrossRef] [PubMed]

34. Cai, M.-Q.; Su, J.; Hu, J.-Q.; Wang, Q.; Dong, C.-Y.; Pan, S.-D.; Jin, M.-C. Planar graphene oxide-based magnetic ionic liquid nanomaterial for extraction of chlorophenols from environmental water samples coupled with liquid chromatography-tandem mass spectrometry. J. Chromatogr. A 2016, 1459, 38-46. [CrossRef] [PubMed]

35. Huang, Y.; Wang, Y.; Wang, Y.; Pan, Q.; Ding, X.; Xu, K.; Li, N.; Wen, Q. Ionic liquid-coated fe3o4/aptes/graphene oxide nanocomposites: Synthesis, characterization and evaluation in protein extraction processes. RSC Adv. 2016, 6, 5718-5728. [CrossRef]

36. Ding, X.; Wang, Y.; Wang, Y.; Pan, Q.; Chen, J.; Huang, Y.; Xu, K. Preparation of magnetic chitosan and graphene oxide-functional guanidinium ionic liquid composite for the solid-phase extraction of protein. Anal. Chim. Acta 2015, 861, 36-46. [CrossRef] [PubMed]

37. Sun, W.; Li, L.; Luo, C.; Fan, L. Synthesis of magnetic graphene nanocomposites decorated with ionic liquids for fast lead ion removal. Int. J. Biol. Macromol. 2016, 85, 246-251. [CrossRef] [PubMed]

38. Wen, Q.; Wang, Y.; Xu, K.; Li, N.; Zhang, H.; Yang, Q.; Zhou, Y. Magnetic solid-phase extraction of protein by ionic liquid-coated fe@graphene oxide. Talanta 2016, 160, 481-488. [CrossRef] [PubMed]

39. Lotfi, Z.; Mousavi, H.Z.; Sajjadi, S.M. Covalently bonded double-charged ionic liquid on magnetic graphene oxide as a novel, efficient, magnetically separable and reusable sorbent for extraction of heavy metals from medicine capsules. RSC Adv. 2016, 6, 90360-90370. [CrossRef]

40. Wu, J.; Zhao, H.; Xiao, D.; Chuong, P.-H.; He, J.; He, H. Mixed hemimicelles solid-phase extraction of cephalosporins in biological samples with ionic liquid-coated magnetic graphene oxide nanoparticles coupled with high-performance liquid chromatographic analysis. J. Chromatogr. A 2016, 1454, 1-8. [CrossRef] [PubMed]

41. Kazemi, E.; Haji Shabani, A.M.; Dadfarnia, S.; Abbasi, A.; Rashidian Vaziri, M.R.; Behjat, A. Development of a novel mixed hemimicelles dispersive micro solid phase extraction using 1-hexadecyl-3-methylimidazolium bromide coated magnetic graphene for the separation and preconcentration of fluoxetine in different matrices before its determination by fiber optic linear array spectrophotometry and mode-mismatched thermal lens spectroscopy. Anal. Chim. Acta 2016, 905, 85-92. [PubMed]

42. Cao, X.; Shen, L.; Ye, X.; Zhang, F.; Chen, J.; Mo, W. Ultrasound-assisted magnetic solid-phase extraction based ionic liquid-coated fe3o4@graphene for the determination of nitrobenzene compounds in environmental water samples. Analyst 2014, 139, 1938-1944. [CrossRef] [PubMed]

43. Aliyari, E.; Alvand, M.; Shemirani, F. Modified surface-active ionic liquid-coated magnetic graphene oxide as a new magnetic solid phase extraction sorbent for preconcentration of trace nickel. RSC Adv. 2016, 6, 64193-64202. [CrossRef]

44. Farzin, L.; Shamsipur, M.; Sheibani, S. Solid phase extraction of hemin from serum of breast cancer patients using an ionic liquid coated fe3o4/graphene oxide nanocomposite, and its quantitation by using faas. Microchim. Acta 2016, 183, 2623-2631. [CrossRef]

45. Chen, Y.; Cao, S.; Zhang, L.; Xi, C.; Li, X.; Chen, Z.; Wang, G. Preparation of size-controlled magnetite nanoparticles with a graphene and polymeric ionic liquid coating for the quick, easy, cheap, effective, rugged and safe extraction of preservatives from vegetables. J. Chromatogr. A 2016, 1448, 9-19. [CrossRef] [PubMed] 
46. Alvand, M.; Shemirani, F. Fabrication of fe3o4@graphene oxide core-shell nanospheres for ferrofluid-based dispersive solid phase extraction as exemplified for cd(ii) as a model analyte. Microchim. Acta 2016, 183, 1749-1757. [CrossRef]

47. Chen, F.; Song, Z.; Nie, J.; Yu, G.; Li, Z.; Lee, M. Ionic liquid-based carbon nanotube coated magnetic nanoparticles as adsorbent for the magnetic solid phase extraction of triazole fungicides from environmental water. RSC Adv. 2016, 6, 81877-81885. [CrossRef]

48. Luo, M.; Liu, D.; Zhao, L.; Han, J.; Liang, Y.; Wang, P.; Zhou, Z. A novel magnetic ionic liquid modified carbon nanotube for the simultaneous determination of aryloxyphenoxy-propionate herbicides and their metabolites in water. Anal. Chim. Acta 2014, 852, 88-96. [CrossRef] [PubMed]

49. Wen, Q.; Wang, Y.; Xu, K.; Li, N.; Zhang, H.; Yang, Q. A novel polymeric ionic liquid-coated magnetic multiwalled carbon nanotubes for the solid-phase extraction of $\mathrm{cu}$, zn-superoxide dismutase. Anal. Chim. Acta 2016, 939, 54-63. [CrossRef] [PubMed]

50. Chen, J.; Wang, Y.; Huang, Y.; Xu, K.; Li, N.; Wen, Q.; Zhou, Y. Magnetic multiwall carbon nanotubes modified with dual hydroxy functional ionic liquid for the solid-phase extraction of protein. Analyst 2015, 140, 3474-3483. [CrossRef] [PubMed]

51. Xiao, D.; Yuan, D.; He, H.; Pham-Huy, C.; Dai, H.; Wang, C.; Zhang, C. Mixed hemimicelle solid-phase extraction based on magnetic carbon nanotubes and ionic liquids for the determination of flavonoids. Carbon 2014, 72, 274-286. [CrossRef]

52. Shirani, M.; Semnani, A.; Habibollahi, S.; Haddadi, H. Ultrasound-assisted, ionic liquid-linked, dual-magnetic multiwall carbon nanotube microextraction combined with electrothermal atomic absorption spectrometry for simultaneous determination of cadmium and arsenic in food samples. J. Anal. At. Spectrom. 2015, 30, 1057-1063. [CrossRef]

(C) 2017 by the authors. Licensee MDPI, Basel, Switzerland. This article is an open access article distributed under the terms and conditions of the Creative Commons Attribution (CC BY) license (http:/ / creativecommons.org/licenses/by/4.0/). 